\title{
Rancangan Perbaikan Lingkungan Kerja Dengan Menggunakan Metode 5S Di Bengkel SMK TR Yayasan Pendidikan Sinar Husni
}

\section{Work Environment Repair Planning by Implementing 5S Method in The Workshop at SMK TR of Educational Foundation Sinar Husni}

\author{
Andri Nasution*1), Ratih Maulidina Syahriani'2), dan Joko Susilo3) \\ Fakultas Teknik Universitas Sumatera Utara ${ }^{1)}$ dan Sekolah Tinggi Teknologi Sinar Husni \\ Diterima: September 2021; Disetujui: November 2021; Dipublikasi: November 2021; \\ *Coresponding author : andri.nasution@usu.ac.id
}

\begin{abstract}
Abstrak
Kegiatan praktek belajar di bengkel tidak akan lepas dari berbagai kemungkinan timbulnya kecelakaan kerja. Kecelakaan kerja yang dapat terjadi yaitu luka,baik yang bersifat luka permanen, luka ringan, maupun gangguan kesehatan. Ada potensi bahaya yang mungkin timbul tetapi tidak disadari oleh setiap siswa. Tempat yang paling berisiko dalam lingkungan sekolah adalah bengkel, yang merupakan tempat praktek bagi siswa ataupun bagi guru dalam melakukan bimbingan praktek. Tujuan penelitian yang dilakukan adalah untuk menciptakan kondisi lingkungan kerja yang lebih baik dari sebelumnya pada bengkel SMK TR Yayasan Pendidikan Sinar Husni. Penelitian ini memiliki rangkaian kegiatan yang diawali dengan tinjauan pustaka kemudian dilanjutkan dengan pembuatan lembar identifikasi bahaya yang membahas hubungan antara kegiatan di dalam bengkel dengan potensi bahaya serta solusinya. Langkah selanjutnya adalah dengan menganalisis dan memberikan penilaian risiko terhadap potensi bahaya yang telah diidentifikasi dengan menggunakan metode HIRARC. Hasil penelitian menunjukkan scoring 5S secara keseluruhan terdapat sedikit kesesuaian. Untuk kategori seiso telah mendapat scoring dengan keterangan cukup sesuai. Namun, untuk kategori seiri, seiton seitsuke, dan shitsuke masih mendapat scoring dengan keterangan terdapat sedikit kesesuaian, sehingga perlu dilakukan perbaikan.
\end{abstract}

Kata Kunci : SMK TR Sinar Husni; Keselamatan dan Kesehatan Kerja (K3); Metode 5S; Potensi Bahaya; Penilaian Risiko

\begin{abstract}
Practical learning activities in the workshop will not be separated from the various possibilities of workplace accidents. Work accidents that can occur are injuries, both permanent injuries, minor injuries, and health problems. There are potential dangers that may arise but are not realized by every student. The most risky place in the school environment is the workshop, which is a place of practice for students or for teachers in conducting practical guidance. The purpose of this research is to create a working environment that is better than before in the workshop of SMK TR Sinar Husni Education Foundation. This study has a series of activities that begin with a literature review and then proceed with the creation of a hazard
\end{abstract}


identification sheet that discusses the relationship between activities in the workshop with potential hazards and their solutions. The next step is to analyze and provide a risk assessment of the potential hazards that have been identified using the HIRARC method. The results showed that the overall $5 S$ scoring had a slight suitability. For the seiso category, it has received a score with quite appropriate information. However, for the seiri, seiton seitsuke, and shitsuke categories, they still received a score with the information that there was a slight suitability, so improvements needed to be made.

Keyword : SMK TR Sinar Husni; Occupational Health and Safety (K3); 5 S method; Potential hazard; Risk Assessment

How to Cite: Nasution, Andri, Syahriani, Ratih Maulidina, Susilo, Joko (2021). Rancangan Perbaikan Lingkungan Kerja Dengan Menggunakan Metode 5S Di Bengkel SMK TR Yayasan Pendidikan Sinar Husni. JIME (Journal of Industrial and Manufacture Engineering). 5(2): 148 - 160 
Andri Nasution, Ratih Maulidina Syahriani, Joko Susilo. Rancangan Perbaikan Lingkungan Kerja Dengan Menggunakan Metode 5S Di Bengkel SMK TR Yayasan Pendidikan Sinar Husni

\section{PENDAHULUAN}

Salah satu penyebab seringnya terjadi kecelakaan adalah kurangnya penataan peralatan, barang-barang yang tidak dibutuhkan yang kerap menimbulkan kesulitan ruang gerak siswa yang praktek saat melakukan kegiatan dan dapat menyebabkan terkena dan terjatuhnya siswa karena peralatan dan barang-barang yang berserakan.

Berdasarkan observasi awal diketahui bahwa siswa yang melakukan kegiatan praktek memiliki sumber bahaya yang dapat menimbulkan kecelakaan kerja baik itu bahaya limbah B3, bahaya fisik, bahaya biologis dan bahaya ergonomis. Faktor penyebab kecelakaan kerja selain kesalahan dan kelalaian dalam penggunaan mesin, peralatan yang ada di bengkel, tidak memahami prosedur kerja dengan benar, kurangnya pelatihan kerja, tidak tersedianya peralatan Keselamatan dan Kesehatan Kerja (K3) adalah tidak diterapkannya metode $5 \mathrm{~S}$ yang dapat membantu untuk memperbaiki kondisi tata letak barang-barang di bengkel dan memperbaiki sikap kerja pengguna bengkel.

Berdasarkan cukup tingginya risiko kecelakaan kerja yang dapat terjadi pada bengkel SMK TR Yayasan Pendidikan Sinar Husni, perlu dilakukan identifikasi bahaya mengenai risiko apa saja yang mungkin terjadi dan dampak risikonya, yaitu mengelola risiko untuk mencegah terjadinya kecelakaan kerja atau kejadian yang tidak diinginkan. Identifikasi bahaya tersebut dapat mengurangi peluang terjadinya kecelakaan kerja karena identifikasi bahaya berkaitan dengan faktor penyebab kecelakaan kerja. dengan melakukan identifikasi bahaya maka sumber-sumber bahaya dapat diketahui sehingga kemungkinan kecelakaan dapat dikurangi.

Penelitian ini memiliki rangkaian kegiatan yang diawali dengan tinjauan pustaka yang dilakukan untuk mengumpulkan informasi terkait kondisi lingkungan kerja bengkel SMK TR Yayasan Pendidikan Sinar Husni. Kemudian dilanjutkan dengan penilaian resiko yang digunakan untuk mengidentifikasi potensi bahaya setelah itu dilakukan analisa keselamatan kerja yang membahas hubungan antara kegiatan di dalam bengkel dengan potensi bahaya serta solusinya. Selanjutnya setelah dilakukan penilaian risiko, maka diadakan pretest dengan menggunkan metode 5S dilanjutkan denganpelatihan $5 \mathrm{~S}$ dan post test. Hasil dari penilaian risiko terhadap potensi bahaya yang ada di bengkel dan kegiatan yang dilakukan sampai dengan post test $5 \mathrm{~S}$ akan menjadi masukan untuk perbaikan lingkungan kerja di bengkel SMK TR Yayasan Pendidikan Sinar Husni.

Berdasarkan pernyataan di atas, penulis bermaksud untuk mengadakan penelitian dengan judul adalah "Rancangan Perbaikan Lingkungan Kerja Dengan Menggunakan Metode 5S Di Bengkel SMK TR Yayasan Pendidikan Sinar Husni”.

Tujuan dari penelitian ini adalah mengidentifikasi potensi bahaya yang ada dan melakukan penilaian risiko dengan menggunakan metode HIRARC dengan menerapkan program perbaikan lingkungan kerja dengan metode $5 \mathrm{~S}$ dan memberikan rekomendasi pengendalian untuk mencegah bahaya yang terjadi pada tingkatan risiko tertinggi serta merancang program perbaikan lingkungan kerja di bengkel SMK TR Yayasan Pendidikan Sinar Husni. 
Penelitian ini sangat penting dilakukan karena selama ini pihak sekolah kurang menyadari potensi bahaya yang terdapat di bengkel. Belum adanya data pasti terkait rekayasa lingkungan kerja di lingkungan bengkel SMK TR Yayasan Pendidikan Sinar Husni menjadi alasan utama dilaksanakannya penelitian ini. Beberapa kecelakaan kerja yang terjadi mengindikasikan bahwa masih kurangnya pemahaman para pengelola bengkel (guru dan siswa/praktikan) tentang pentingnya lingkungan kerja yang baik. Hal ini menunjukkan belum terpenuhi secara keseluruhan program perbaikan lingkungan kerja di bengkel seperti pengetahuan risiko dan pontesi bahaya yang mungkin terjadi pada saat melakukan kegiatan praktik, sehingga perlu dilakukan identifikasi potensi bahaya untuk membantu praktikan dan staf bengkel untuk mengetahui sumber bahaya tersebut.

\section{METODE PENELITIAN}

Penelitian dilakukan dalam beberapa tahap, yang diawali dengan melakukan tinjauan pustaka hingga menghasilkan rekomendasi pengendalian dan evaluasi kesehatan dan keselamatan kerja.

\section{Lingkungan Kerja}

Langkah pertama yang dilakukan adalah survei lingkungan kerja di lingkungan bengkel sekaligus melakukan pengukuran lingkungan fisik seperti pengukuruan kebisingan, pencahayaan dan pengukuran suhu di sekitar lingkungan kerja bengkel.

Lingkungan kerja adalah segala sesuatu yang ada di sekitar pekerja dan dapat mempengaruhi dalam bekerja meliputi pengaturan penerangan, pengontrolan suara gaduh, pengaturan kebersihan tempat kerja dan pengaturan keamanan tempat kerja" (Sukanto dan Gitosudarma 2009), sedangkan menurut Alex S. Nitisemito (2010) "lingkungan kerja adalah sesuatu yang ada di sekitar para pekerja dan dapat mempengaruhi dirinya dalam menjalankan tugas yang dibebankannya. Perusahaan harus dapat memperhatikan kondisi yang ada dalam peusahaan baik di dalam maupun di luar ruangan tempat kerja, sehingga karyawan dapat bekerja dengan lancar dan merasa aman.

\section{HIRARC (Hazard Identification, Risk Assessment and Risk Conrtol)}

Organisasi harus menetapkan prosedur mengenai Identifikasi Bahaya (Hazard Identification), Penilaian Risiko (Risk Assessment) dan menentukan Pengendaliannya (Risk Control) atau disingkat HIRARC. Keseluruhan proses ini disebut juga manajemen risiko (risk management). HIRARC merupakan elemen pokok dalam sistem manajemen keselamatan dan kesehatan kerja yang berkaitan langsung dengan upaya pencegahan dan pengendalian bahaya. Di samping itu, HIRARC harus dilakukan di seluruh aktifitas organisasi untuk menentukan kegiatan organisasi yang mengandung potensi bahaya dan menimbulkan dampak serius terhadap keselamatan dan kesehatan kerja

\section{Penilaian Resiko}

Selanjutnya dilakukan penilaian risiko dengan terlebih dahulu memperkirakan nilai konsekuensi, paparan, dan kemungkinan yang terdapat pada sumber bahaya. Resiko dianalisis dengan menggabungkan perkiraan 
Andri Nasution, Ratih Maulidina Syahriani, Joko Susilo. Rancangan Perbaikan Lingkungan Kerja Dengan Menggunakan Metode 5S Di Bengkel SMK TR Yayasan Pendidikan Sinar Husni

konsekuensi dan kemungkinan dalam konteks pengendalian yang ada. Untuk menghindari penyimpangan dari sumber informasi yang tersedia dan teknik yang digunakan ketika menganalisis konsekuensi dan kemungkinan.

Tabel 1 Kriteria dan Nilai dari Faktor

\begin{tabular}{|c|c|c|}
\hline Tingkatan & Deskripsi & Rating \\
\hline Catastrophe & $\begin{array}{l}\text { Kematian banyak orang, } \\
\text { aktifitas dihentikan, } \\
\text { kerusakan permanen } \\
\text { pada lingkungan luas }\end{array}$ & 100 \\
\hline Disaster & $\begin{array}{l}\text { kematian pada satu } \\
\text { hingga beberapa orang, } \\
\text { kerusakan permanen } \\
\text { pada lingkungan local }\end{array}$ & 50 \\
\hline $\begin{array}{l}\text { Very } \\
\text { Serious }\end{array}$ & $\begin{array}{l}\text { Cacat permanen, } \\
\text { kerusakan temporer } \\
\text { lingkungan local }\end{array}$ & 25 \\
\hline Serious & Cacat nonpermanent & 15 \\
\hline Important & $\begin{array}{l}\text { Dibutuhkan perawatan } \\
\text { medis, terjadi emisi } \\
\text { buangan tetapi tidak } \\
\text { menimbulkan kerusakan } \\
\text { lingkungan }\end{array}$ & 5 \\
\hline Noticeable & $\begin{array}{l}\text { Luka ringan, sakit ringan, } \\
\text { kerugian sedikit, } \\
\text { terhentinya kegiatan } \\
\text { sementara. }\end{array}$ & 1 \\
\hline
\end{tabular}

Tabel 2 Kriteria dan Nilai dari Faktor Probability

\begin{tabular}{|c|c|c|}
\hline Tingkatan & Deskripsi & $\begin{array}{c}\text { Ratin } \\
\text { g }\end{array}$ \\
\hline $\begin{array}{l}\text { Almost } \\
\text { Certain }\end{array}$ & $\begin{array}{l}\text { Kejadian yang hampir } \\
\text { terjadi jika ada kontak } \\
\text { dengan bahaya }\end{array}$ & 10 \\
\hline Likely & $\begin{array}{l}\text { Kemungkinan terjadinya 50- } \\
50\end{array}$ & 6 \\
\hline $\begin{array}{l}\text { Unusual } \\
\text { but } \\
\text { possible }\end{array}$ & $\begin{array}{l}\text { Suatu kejadian yang tidak } \\
\text { biasa namun masih } \\
\text { memiliki kemungkinan } \\
\text { untuk terjadi }\end{array}$ & 3 \\
\hline $\begin{array}{l}\text { Remotely } \\
\text { Possible }\end{array}$ & $\begin{array}{l}\text { Suatu kejadian yang sangat } \\
\text { kecil kemungkinan } \\
\text { terjadinya }\end{array}$ & 1 \\
\hline $\begin{array}{l}\text { Conceivabl } \\
e\end{array}$ & $\begin{array}{l}\text { Tidak pernah terjadi } \\
\text { walaupun telah bertahun- } \\
\text { tahun }\end{array}$ & 0,5 \\
\hline
\end{tabular}

Practically Secara nyata belum pernah Impossible terjadi

\begin{tabular}{|c|c|c|}
\hline Tingkatan & Deskripsi & Rating \\
\hline Continously & $\begin{array}{l}\text { Beberapa terjadi dalam } \\
\text { sehari (terus menerus) }\end{array}$ & 10 \\
\hline Frequently & $\begin{array}{l}\text { Sekali terjadi dalam } \\
\text { sehari (sering) }\end{array}$ & 6 \\
\hline Occasionally & $\begin{array}{l}\text { Sekali dalam seminggu } \\
\text { sampai sekali dalam } \\
\text { sebulan (kadang-kadang) }\end{array}$ & 3 \\
\hline Infrequent & $\begin{array}{l}\text { Sekali dalam sebulan } \\
\text { hingga sekali dalam } \\
\text { setahun (tidak sering) }\end{array}$ & 2 \\
\hline Rare & $\begin{array}{l}\text { diketahui pernah terjadi } \\
\text { (jarang) }\end{array}$ & 1 \\
\hline Very rare & $\begin{array}{l}\text { Tidak diketahui } \\
\text { terjadinya (sangat jarang) }\end{array}$ & 0,5 \\
\hline
\end{tabular}

0,1 (1) Penentuan tingkat resiko dilakukan setelah ketiga komponen resiko (Konsekuensi, paparan, dan kemungkinan) telah ditentukan besarannya. Untuk menentukan tingkat resiko maka dilakukan pengalian terhadap ketiga komponen risiko tersebut berdasarkan rumus berikut:

Level of risk $=$ Consequences $\mathrm{x}$ Exposure $\mathrm{x}$ Likelihood

Dari hasil perhitungan level of risk di atas kemudian dikelompokkan sesuai kriteria tingkat resiko.

Tabel 4 Skala Tingkatan Risiko

\begin{tabular}{|c|c|c|}
\hline Tingkatan & Deskripsi & Tindakan \\
\hline$>350$ & Very high & $\begin{array}{l}\text { Penghentian } \\
\text { aktifitas sampai } \\
\text { tingkat risiko } \\
\text { dikurangi }\end{array}$ \\
\hline $180-350$ & Priority & $\begin{array}{l}\text { Memerlukan } \\
\text { penanganan } \\
\text { secepatnya }\end{array}$ \\
\hline $70-180$ & Substantial & $\begin{array}{l}\text { Mengharuskan } \\
\text { perbaikan }\end{array}$ \\
\hline $20-70$ & Priority 3 & $\begin{array}{l}\text { Memerlukan } \\
\text { perhatian }\end{array}$ \\
\hline$<20$ & Acceptable & $\begin{array}{l}\text { Lakukan kegiatan } \\
\text { seperti biasa }\end{array}$ \\
\hline
\end{tabular}




\section{Metode 5S}

Prinsip 5S (Seiri, Seiton, Seiso, Seiketsu dan Shitsuke) bisa diguakan untuk dijadikan dasar dalam membangun tempat kerja yang aman dan nyaman Nugraha, (Aditya Saefulloh. 2015). Program housekeeping merupakan suatu hal yang sudah semestinya diterapkan dan melekat dalam kegiatan sehari-hari. Namun, merupakan suatu fakta dalam rutinitas sehari-hari, banyak orang yang mengabaikan hal-hal yang berkaitan dengan tata rumah tangga (housekeeping) ini. Kunci keberhasilan penerapan housekeeping adalah komitmen dan kesungguhan seluruh jajaran perusahaan untuk secara professional dalam sikap dan perilaku menerapkan prinsip housekeeping (5R).

\section{Konsep Seiri (Ringkas)}

Seiri yaitu memisahkan benda yang diperlukan dengan yang tidak diperlukan, kemudian menyingkirkan yang tidak diperlukan (ringkas).

\section{Konsep Seiton (Rapi)}

Seiton yaitu menyusun dengan rapih dan mengenali benda untuk mempermudah penggunaan. Kata Jepang " seiton" secara harafiah berarti menyusun benda dengan cara yang menarik (rapi). Dalam konteks $5 \mathrm{~S}$, ini berarti mengatur barang-barang sehingga setiap orang dapat menemukannya dengan cepat.

\section{Konsep Seiso (Resik)}

Seiso yaitu selalu membersihkan, menjaga kerapihan dan kebersihan (resik). Ini adalah proses pembersihan dasar dimana suatu daerah disapu dan kemudian dipel dengan kain pel. Karena lantai, jendela, maupun dinding harus dibersihkan, seiso di sini setara dengan aktifitas pembersihan berskala besar yang dilakukan setiap akhir tahun di rumah tangga Jepang.

\section{Konsep Seiketsu (Rawat)}

Seiketsu yaitu terus menerus mempertahankan $3 \mathrm{~S}$ tersebut diatas, yakni Seiri, Seiton, dan Seiso. Seiketsu atau rawat, pada prinsipnya mengusahakan agar tempat kerja yang sudah menjadi baik dapat selalu terpelihara. Di tempat kerja yang rawat, kerawanan dan penyimpangan dapat segera dikenali, sehingga berbagai masalah dapat dicegah sedini mungkin.

\section{Konsep Shitsuke (Rajin)}

Shitsuke yaitu metode yang digunakan untuk memotivasi pekerja agar terus menerus melakukan dan ikut serta dalam kegiatan perawatan dan aktivitas perbaikan serta membuat pekerja terbiasa mentaati aturan (rajin). Shitsuke atau rajin berkaitan dengan kebiasaan karyawan yang harus dibina agar dapat menjaga dan meningkatkan apa yang sudah baik. Seperti, budaya antri, bersih, tepat waktu, tepat janji dan sebagainya harus dibina. Orang yang dapat memberikan kritik membangun dengan baik akan dapat melaksanakannya juga (Salim: 2002).

\section{Penilaian Penerapan Prinsip 5S}

Pada lembar checklist terdapat butir-butir pertanyaan yang disusun berdasarkan hal yang harus diperhatikan dalam konsep $5 \mathrm{~S}$ dan penyesuaian terhadap kondisi lingkungan kerja yang di teliti. Penilaian didasarkan pada pengamatan langsung pada bengkel SMK TR Yayasan Pendidikan Sinar Husni. 
Andri Nasution, Ratih Maulidina Syahriani, Joko Susilo. Rancangan Perbaikan Lingkungan Kerja Dengan Menggunakan Metode 5S Di Bengkel SMK TR Yayasan Pendidikan Sinar Husni

Rentang penilaian skor $5 S$ adalah sebagai berikut:

$0=$ Tidak terdapat kesesuaian

$1=$ Terdapat sedikit kesesuaian

2 = Cukup sesuai

$3=$ Sesuai

4 = Sangat Sesuai

Contoh hasil pengamatan dapat dilihat pada Tabel 1

Tabel 5. Scoring 5S

\begin{tabular}{|c|c|c|c|c|c|c|c|c|}
\hline \multirow{2}{*}{ No } & \multirow{2}{*}{ Kategori } & \multirow{2}{*}{ Kriteria } & \multicolumn{4}{|c|}{ Skor } & \multirow{2}{*}{$\begin{array}{c}\text { Catatan } \\
\text { Temuan }\end{array}$} & \multirow{2}{*}{$\begin{array}{c}\text { Ketera } \\
\text { ngan }\end{array}$} \\
\hline & & & $\begin{array}{ll}0 & 1\end{array}$ & 2 & 3 & 4 & & \\
\hline 1 & Seiri & & & & & & & \\
\hline 2 & Seiton & & & & & & & \\
\hline 3 & Seiso & & & & & & & \\
\hline 4 & Seiketsu & & & & & & & \\
\hline 5 & Shitsuke & & & & & & & \\
\hline & Skor & & $-\quad-$ & - & - & - & & \\
\hline
\end{tabular}

Dilanjutkan

mengembangkan solusi alternatif memberikan rekomendasi pengendalian yang belum dilaksanakan dengan mempertimbangkan kemungkinan pengaplikasiannya. Bagan alir penelitian terapan dapat dilihat pada Gambar Diagram Fishbone Penelitian.

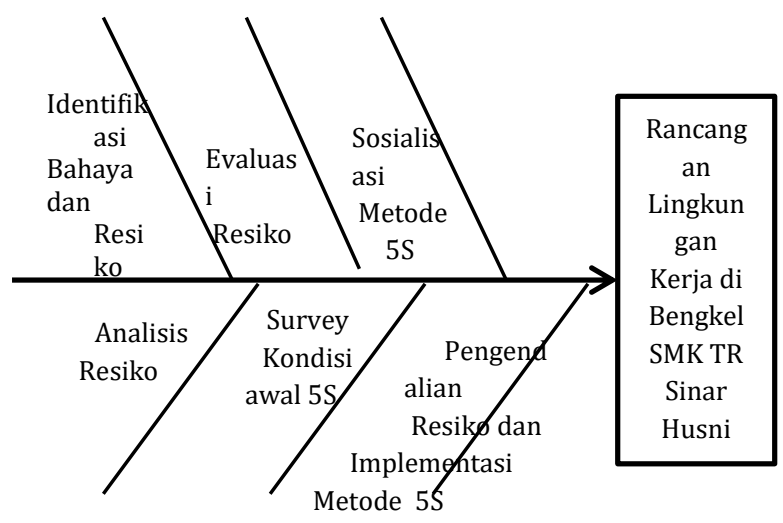

Gambar 1 Diagram Fishbone Penelitian

\section{HASIL DAN PEMBAHASAN}

\section{Hasil Pengamatan}

Berdasarkan hasil pengamatan dapat diketahui penyebab yang dapat menyebabkan gangguan dalam proses kerja dibengkel SMK TR Sinar Husni diantaranya :

1. Lingkungan Kerja

Ditinjau dari aspek lingkungan kerja, terdapat beberapa keadaan seperti belum adanya batas yang jelas pada tempat penyimpanan, terdapat material yang tidak dibutuhkan pada area kerja, kondisi warehouse khususnya area spare part kotor dan berdebu, serta item-item belum disimpan sesuai tempatnya.

\section{Bahan Baku}

Bahan baku menentukan kualitas dari output produk akhir. Ditinjau dari aspek bahan baku, terdapat beberapa keadaan seperti tidak diberikan penanda keterangan jenis bahan, dan terkadang kualitas bahan tidak sesuai standar.

\section{Manusia}

Manusia merupakan salah satu faktor yang dapat menyebabkan kesalahan dalam produksi. Ditinjau dari aspek manusia, terdapat beberapa keadaan seperti kurang teliti dalam melakukan pekerjaan, serta kurangnya pengetahuan siswa tentang sifat material produksi, sehingga terjadi kerusakan pada alat dan bahan.

\section{Metode Kerja}

Metode kerja sangat menentukan produktivitas kerja yang dihasilkan. Ditinjau dari aspek metode kerja, terdapat beberapa keadaan seperti SOP tidak dijalankan dengan baik, serta kurangnya teknik keterampilan operator dalam melakukan pekerjaan.

\section{Mesin dan Peralatan Produksi}


Ditinjau dari aspek metode kerja, terdapat beberapa keadaan seperti terdapat mesin produksi yang tidak dijalankan akibat kerusakan, serta terdapat mesin dan peralatan produksi yang tidak ditempatkan pada tempat yang sesuai.

Ditinjau dari aspek 5S, permasalahan penerapan prinsip $5 S$ yang ditemukan pada dibengkel SMK TR Sinar Husni adalah sebagai berikut.

Tabel 6. Permasalahan Penerapan Prinsip 5S yang Ditemukan pada Bengkel SMK TR Sinar

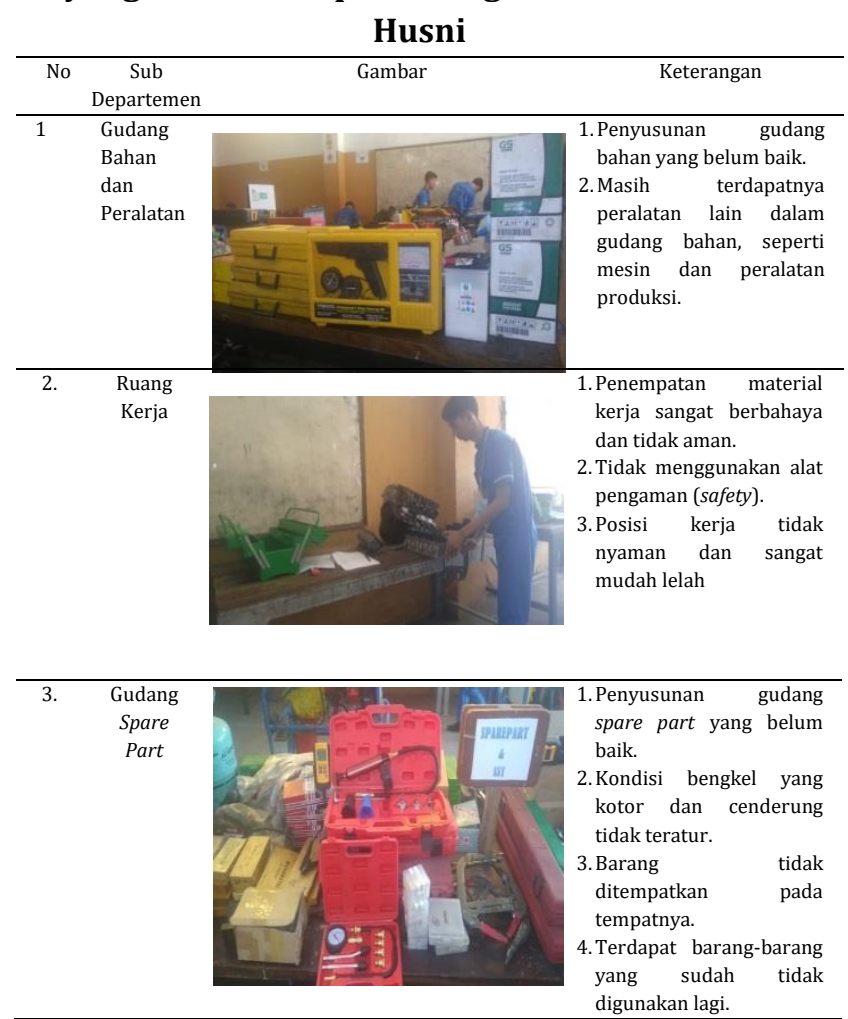

Tabel 7. Scoring 5S di Bengkel SMK TR Sinar Husni

\begin{tabular}{|c|c|c|c|c|c|c|}
\hline \multirow{2}{*}{ No } & \multirow{2}{*}{ Kategori } & \multirow{2}{*}{ Kriteria } & \multicolumn{2}{|r|}{ Skor } & \multirow[t]{2}{*}{ Catatan Temuan } & \multirow{2}{*}{ Keterangan } \\
\hline & & & 0 & 12234 & & \\
\hline 1 & & $\begin{array}{lr}\text { Tidak terdapat } & \text { alat/ } \\
\text { material yang tidak } \\
\text { dibutuhkan }\end{array}$ & & $\checkmark$ & $\begin{array}{l}\text { Terdapat alat/material } \\
\text { yang tidak dibutukan, } \\
\text { seperti alat/material yang } \\
\text { tidak digunakan lagi }\end{array}$ & $\begin{array}{l}\text { Terdapat sedikit } \\
\text { kesesuaian }\end{array}$ \\
\hline 2 & Seiri & $\begin{array}{l}\text { Terdapat SOP tertulis } \\
\text { untuk eliminasi atau } \\
\text { pembuangan item-item } \\
\text { yang tidak diperlukan }\end{array}$ & & $\checkmark$ & $\begin{array}{l}\text { Sudah terdapat SOP } \\
\text { tertulis untuk eliminasi } \\
\text { atau pembuangan item- } \\
\text { item yang tidak diperlukan }\end{array}$ & Sesuai \\
\hline 3 & & $\begin{array}{lr}\text { Semua item yang tidak } \\
\text { dipakai } & \text { mudah } \\
\text { diidentifikasi } & \end{array}$ & & $\checkmark$ & $\begin{array}{l}\text { Item yang tidak dipakai } \\
\text { sulit diidentifikasi karena } \\
\text { ditempatkan bercampur }\end{array}$ & $\begin{array}{l}\text { Terdapat } \\
\text { kesesuaian }\end{array}$ \\
\hline
\end{tabular}

Sumber : Pengolahan Data

\section{Penilaian Penerapan Prinsip 5S}

Pada lembar checklist terdapat butir-butir pertanyaan yang disusun berdasarkan hal yang harus diperhatikan dalam konsep $5 \mathrm{~S}$ dan penyesuaian terhadap kondisi departemen warehouse. Penilaian didasarkan pada pengamatan langsung pada departemen warehouse. Rentang penilaian skor 5S adalah sebagai berikut:

$0=$ Tidak terdapat kesesuaian

$1=$ Terdapat sedikit kesesuaian

$2=$ Cukup sesuai

$3=$ Sesuai

4 = Sangat Sesuai

Hasil pengamatan dapat dilihat pada Tabel 7. 
Andri Nasution, Ratih Maulidina Syahriani, Joko Susilo. Rancangan Perbaikan Lingkungan Kerja Dengan Menggunakan Metode 5S Di Bengkel SMK TR Yayasan Pendidikan Sinar Husni

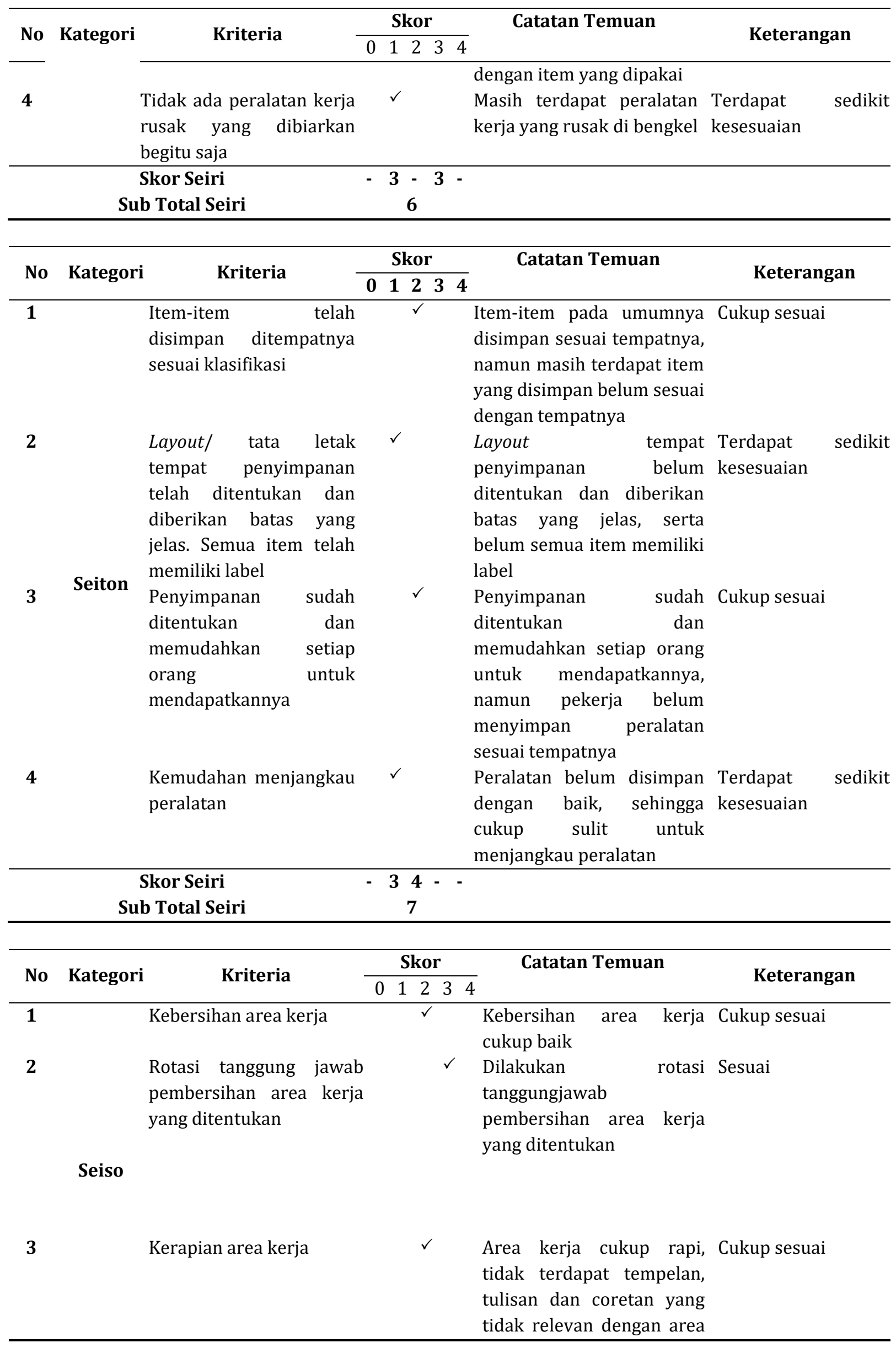




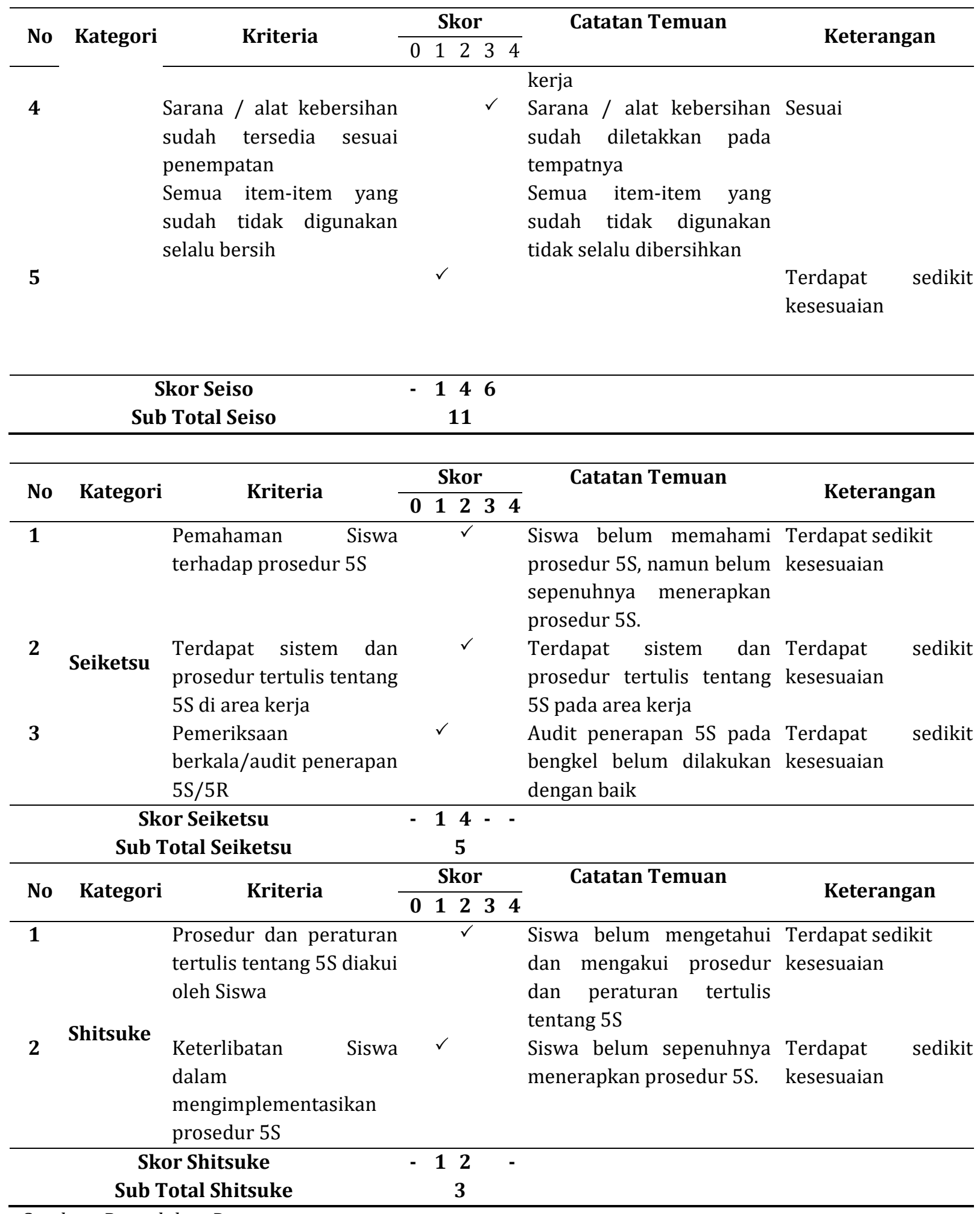

Sumber : Pengolahan Data

Rekapitulasi hasil scoring ditunjukkan pada tabel berikut ini. 
Andri Nasution, Ratih Maulidina Syahriani, Joko Susilo. Rancangan Perbaikan Lingkungan Kerja Dengan Menggunakan Metode 5S Di Bengkel SMK TR Yayasan Pendidikan Sinar Husni

Tabel 8. Rekapitulasi Hasil Scoring 5S Bengkel SMK TR Sinar Husni

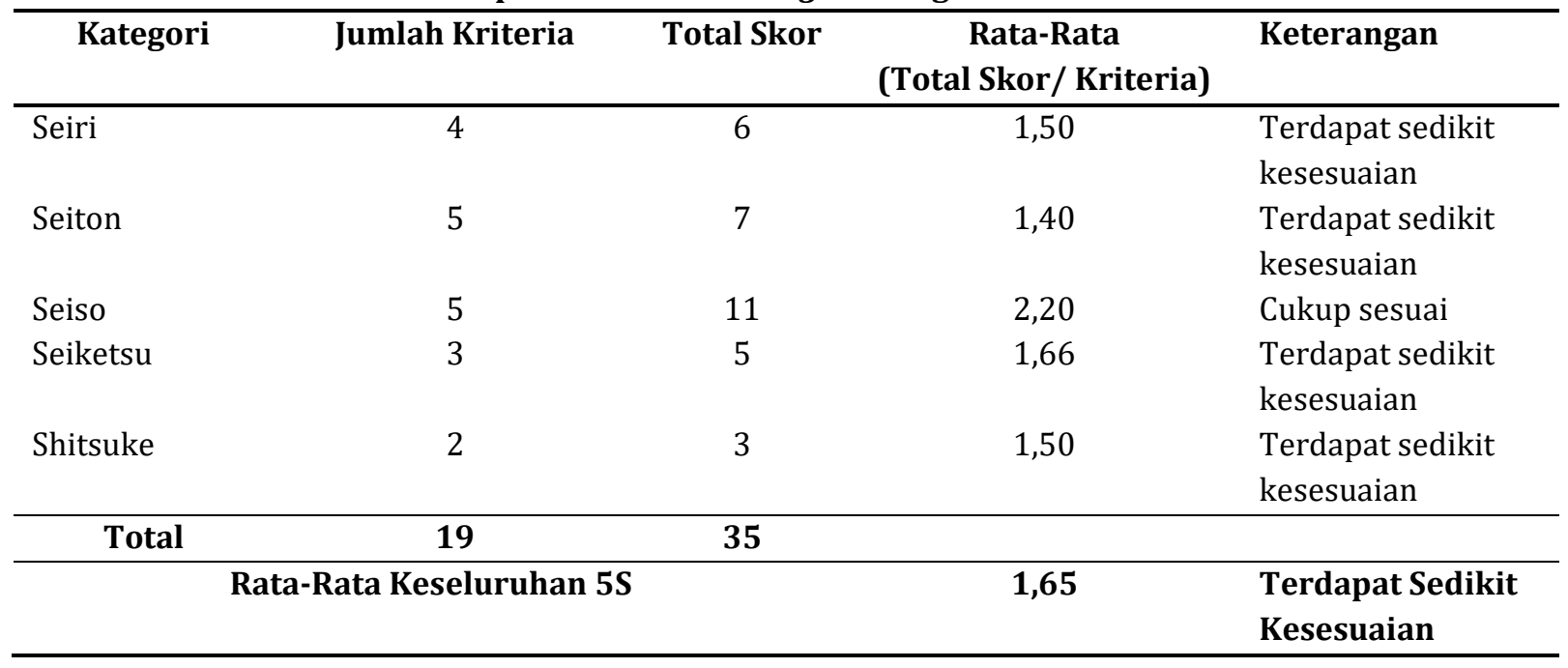

Berdasarkan tabel diatas, hasil scoring 5S secara keseluruhan, antara dan catatan temuan termasuk dalam kategori terdapat sedikit kesesuaian. Untuk kategori seiso telah mendapat scoring dengan keterangan cukup sesuai. Namun, untuk kategori seiri, seiton seitsuke, dan shitsuke masih mendapat scoring dengan keterangan terdapat sedikit kesesuaian, sehingga perlu dilakukan perbaikan.

\section{Pemecahan Masalah}

Seiri, Seiton, Seiso, Seiketsu dan Shitsuke merupakan suatu sistem yang digunakan untuk mengurangi pemborosan dan mengoptimalkan produktivitas melalui pemeliharaan tempat kerja yang terorganisir dan isyarat visual untuk mencapai hasil yang lebih baik. Oleh sebab itu, pemecahan masalah pada bengkel dapat dilakukan dengan mengimplementasikan prinsip 5S.

\section{Seiri (Ringkas/Pemilahan)}

Menurut Farahdina (2017) seiri adalah mengatur segala sesuatu, memilah sesuai dengan aturan atau prinsip-prinsip yang spesifik. Permasalahan yang dihadapi oleh Bengkel SMK TR Sinar Husni adalah pada gudang bahan terdapat peralatan lain dalam gudang bahan, seperti mesin dan peralatan. Sedangkan pada gudang spare part terdapat barang-barang yang sudah tidak digunakan lagi. Dan juga masih terdapat peralatan kerja yang rusak di gudang. Diperlukan upaya untuk membersihkan gudang dan pemilahan terhadap item-item yang tidak digunakan lagi.

\section{Seiton (Penataan)}

Menurut Farahdina (2017) seiton berarti menyimpan barang-barang di tempat yang tepat atau dalam tata letak yang benar sehingga dapat dipergunakan dalam keadaan mendadak. Item-item pada gudang spare part belum sepenuhnya tersusun dengan baik sesuai dengan tempat peralatan yang seharusnya. Hal ini dikarenakan kurangnya kesadaran siswa untuk mengembalikan item yang diambil dari ruang spare part pada tempatnya. Sehingga perlu dilakukan penataan dengan menempatkan item yang sama pada satu tempat dengan memperhatikan kemudahan dalam menjangkau item 
tersebut. Misalnya baut ditempatkan pada tempat yang sama sesuai dengan jenis bautnya, bagian-bagian dari kunci ditempatkan pada tempat yang sama agar mudah dijangkau, pipa ditempatkan pada tempat yang sama..

\section{Seiso (Pembersihan)}

Menurut Farahdina (2017) seiso berarti melakukan pembersihan sehingga segala sesuatunya bersih. Untuk meningkatkan kebersihan area kerja, maka perlu dilakukan inspeksi kebersihan secara berkala setiap hari.

\section{Seiketsu (Pemantapan)}

Menurut Farahdina (2017) seiketsu berarti perawatan ringkas, kerapian, dan kebersihan secara terus menerus. Hal tersebut meliputi kebersihan personil dan kebersihan secara terus menerus. Adapun kegiatan yang dapat dilakukan untuk meningkatkan seiketsu adalah dengan menekankan pada operator untuk menerapkan budaya $5 \mathrm{~S}$ di lingkungan kerja, serta dengan menerapkan sistem reward dan punishment untuk mempertahankan kondisi area kerja yang bersih dan rapi. Reward yang diberikan dapat berupa pujian, penghargaan, bonus, dsb. Sedangkan punishment yang dapat diberikan seperti teguran lisan maupun tulisan, dan jika masih dilanggar dapat memberikan punishment misalnya dengan pemotongan gaji.

\section{Shitsuke (Pembiasaan)}

Menurut Farahdina (2017) shitsuke berarti pelatihan yang diberikan dan kemampuan untuk melakukan sesuatu yang diinginkan. Langkah yang dapat dilakukan untuk mengatasi hal ini adalah dengan melakukan audit 5S secara berkala dan upaya peningkatan kesadaran operator untuk menerapkan budaya $5 \mathrm{~S}$ di lingkungan kerja.

Telah dihasilkan usulan perbaikan dengan penerapan metode $5 S$ pada Bengkel SMK TR Sinar Husni. Akan tetapi, masih belum dilakukan perbaikan dengan menggunakan prinsip 5S tersebut, dikarenakan pihak sekolah hanya memberikan izin untuk melakukan penelitian saja dan tidak mengijinkan untuk memperbaiki lingkungan kerja Bengkel SMK TR Sinar Husni karena akan membutuhkan waktu pengerjaan dan pada akhirnya akan mengganggu kegiatan praktikum siswa yang setiap harinya melakukan aktivitas di bengkel tersebut

\section{SIMPULAN}

Berdasarkan hasil ulasan diatas dapat disimpulkan bahwa:

1. Pada gudang bahan terdapat peralatan lain dalam gudang bahan, seperti mesin dan peralatan. Sedangkan pada gudang spare part terdapat barang-barang yang sudah tidak digunakan lagi.

2. Kurangnya kesadaran siswa untuk mengembalikan item yang diambil dari ruang spare part pada tempatnya mengakibatkan penataan menjadi perlu dilakukan.

3. Kebersihan area kerja, maka perlu dilakukan inspeksi kebersihan secara berkala setiap hari.

4. Perlu menerapkan sistem reward dan punishment untuk mempertahankan kondisi area kerja yang bersih dan rapi.

5. Langkah yang dapat dilakukan untuk mengatasi masalah pembiasaan adalah dengan melakukan audit 5S secara berkala dan upaya peningkatan kesadaran operator untuk menerapkan 
Andri Nasution, Ratih Maulidina Syahriani, Joko Susilo. Rancangan Perbaikan Lingkungan Kerja Dengan Menggunakan Metode 5S Di Bengkel SMK TR Yayasan Pendidikan Sinar Husni

budaya 5S di lingkungan kerja.

\section{DAFTAR PUSTAKA}

Alex S. Nitisemito, (2010). Manajemen Personalia: Manajemen Sumber Daya Manusia, Ed.3, Ghalia Indonesia, Jakarta.

B. Purwanggono, R. Ruminta and S. Irawati, (2014). "Analisis Faktor-faktor yang Memengaruhi Motivasi Karyawan dalam Menerapkan Budaya Kerja 5 s (Studi Kasus pada Karyawanpt. Pln (Persero) P3jb App Semarang)," Prosiding SNATIF, pp. 57-68.

Faradina, N. (2017). Pengaruh Program Gerakan Literasi Sekolah terhadap Minat Baca Siswa di SD IslamTerpaduMuhammadiyah An Najah Jatinom Klaten. Google Scholar: Jurnal Hanata Widya Volume 6 Tahun 2017

H.Kurniawan, (2013)."Studi Deskriptif Manajemen Kualitas dengan Metode $5 S$ di Gudang Hypermarket X Surabaya," CALYPTRA, vol. 2, no. 2, pp. 1-20.

Nugraha, Aditya dkk. (2015). Usulan Perbaikan Berdasrkan Metode $5 S$ (Seiri, Seiton, Seiso, SSeiketsu, Shitsuke) untuk area kerja lantai produksi di PT.X. Bandung. Vol 03. No 04.

Restuputri, Dian Palupi Dika Wahyudin . (2019). Penerapan 5s (Seiri, Seiton, Seiso, Seiketsu,
Shitsuke) Sebagai Upaya Pengurangan Waste Pada Pt X Jurnal Sistem Teknik Industri (JSTI) Vol. 21, No. 1, 2019| 51 - 63.

Salim, Emil. Green Company, (2002). Pedoman Pengelolaan Lingkungan, Keselamatan, dan Kesehatan Kerja (LK3). Jakarta. PT.Astra International Tbk: 2002 pada 29 September 2012 dari repository.ipb.ac.id/handle/123456789/5 7093

Sugiyono, (2014). Metode Penelitian Pendidikan Pendekatan Kuantitatif, Kualitatif Dan R\&D. Alfabeta, Bandung.

Sharma, kshitij mohan. Surabhi Lata, (2017). Effectuation of Lean Tool " $5 S$ " on Materials and Work Space Efficiency in a Copper Wire Drawing Micro-Scale Industry in India.india. Proceedings 5 (2018) 4678-4683

Sukanto dan Gitosudarma, (2009). Manajemen Produksi, Ed. 4, BPFE-Yogyakarta.

Polewangi, Y.D, Sari, A (2020).Analisis Pengukuran Iklim Keselamatan PAsien Instansi Gawat Darurat di Rumah Sakit Umum Daerah (RSUD) Deli Serdang. Universitas Medan Area. 